\title{
A Minimal Visual Restriction Experiment: Preventing Chicks from Seeing their Feet Affects Later Responses to Mealworms
}

\author{
JOSH WALLMAN \\ Institute of Animal Behavior \\ Rutgers University \\ Newark, New Jersey
}

\begin{abstract}
Chicks raised from hatching for 2 days without being able to see their feet because of cloth foot covers were less likely than controls to eat or pick up mealworms, which resemble the chicks' feet in some respects. Instead the chicks spent much time staring at the mealworms. Similar, but perhaps weaker, effects were obtained when the toes were simply painted black. These results may reflect processes of perceptual learning characteristic of infant animals.
\end{abstract}

The perceptual development of a young animal can be profoundly influenced by the nature of its early visual experiences. At one extreme, animals raised without form vision have difficulty with a variety of perceptual tasks (Chow \& Steward, 1972) and kittens raised with their visual experience limited to, for example, vertical stripes have some impairment of their perception of horizontal lines (Hirsch, 1972; Muir \& Mitchell, 1975). At the other extreme, animals raised in complex sensory environments show enhanced abilities at perceptual discrimination (Forgus, 1954).

The effect of early visual experience is not simply to facilitate perception of those objects present in the early environment, but also to facilitate perception of other objects that have some attributes in common with the objects seen. From this point of view, everything the animal sees might influence to a greater or lesser extent its perceptual development.

This paper reports the effect of a very minor deprivation of early visual experience: chicks were prevented from seeing their toes for 3 days. They were observed on the 2 nd and 3 rd day in the presence of a mealworm (Tenebrio larva), which resembles their toes in size, color, and pattern of segmentation, but differs in manner of movement and significance to the chick. The hypothesis tested was that the chicks that had seen their toes would be perceptually "prepared" for the mealworms and would eat them with little delay, whereas to the chicks that had not seen their toes the mealworm would be a rather strange sight and would be examined more and eaten less often.

Address correspondence to Josh Wallman, Biology Department, City College, 138th St. and Convent Ave., New York, N.Y. 10031, U.S.A.

Received for publication 31 August 1977

Revised for publication 22 February 1978

Developmental Psychobiology, 12(4):391-397 (1979)

(C) 1979 by John Wiley \& Sons, Inc.

$0012-1630 / 79 / 0012-0391 \$ 01.00$ 


\section{Methods}

White Leghom chicks (Gallus gallus domesticus) hatched in the dark in an incubator were removed at less than $12 \mathrm{hr}$ of age with their heads covered by a cloth hood to prevent pattern vision. Alternate chicks were either simply handled or had white foot covers put on. The foot covers (Fig. 1) were pieces of white rayon cloth (taffeta), cut in the shape of the outline of a chick's foot (that is, the pear shape obtained by connecting the points representing the tips of each toe) with a small hole to accommodate the tarsus. The foot covers were attached with cyanoacrylate glue only at the distal end of each toe. Each foot was placed on the table surface with the toes in a natural extended position before the foot covers were attached, thereby assuring that they did not impair the chick's ability to walk. Only chicks whose foot coverings stayed in place for both tests are included in this study.

All chicks were kept in individual, uncovered cardboard cylinders $25 \mathrm{~cm}$ in diameter and $30 \mathrm{~cm}$ high (commercial 5 gallon ice cream containers), the floors of which were covered with $3.1 \mathrm{~mm}$ thick yellowish-white polyurethane foam. Each had a small water tube penetrating the wall of the cylinder, but no food. Thus the chicks could not see other chicks but could see the contents of the container, the ceiling and upper walls of the room, and, from time to time, the experimenter. The room was maintained at approximately $32^{\circ} \mathrm{C}$.

\section{Testing}

At 2 days of age, 4 days of daily tests started. For each test the chick was moved to a container identical to its rearing container in an adjacent room (maintained at about $24^{\circ} \mathrm{C}$ ) and left for $5-10 \mathrm{~min}$ to accommodate. Then a $20-25-\mathrm{mm}$ mealworm in a $6-\mathrm{cm}$ watchglass was added and the 5-min observation period started. The mealworm in the watchglass provided a good stimulus situation because the mealworm kept climbing up the sloping sides of the dish although the slope was such that it could not, usually, escape from the dish (Hogan, 1965). The chick's behavior was recorded with a WRATS keyboard for subsequent computer transcription and analysis (White, 1971).

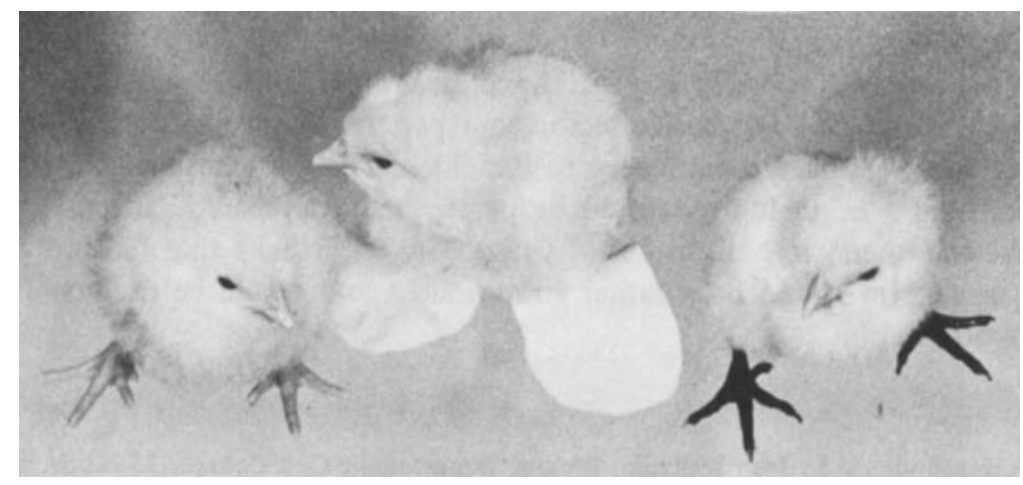

Fig. 1. Appearance of animals in the 3 groups. Left, normal. Center, foot-covered group (first experiment). Right, foot-painted group (second experiment). 

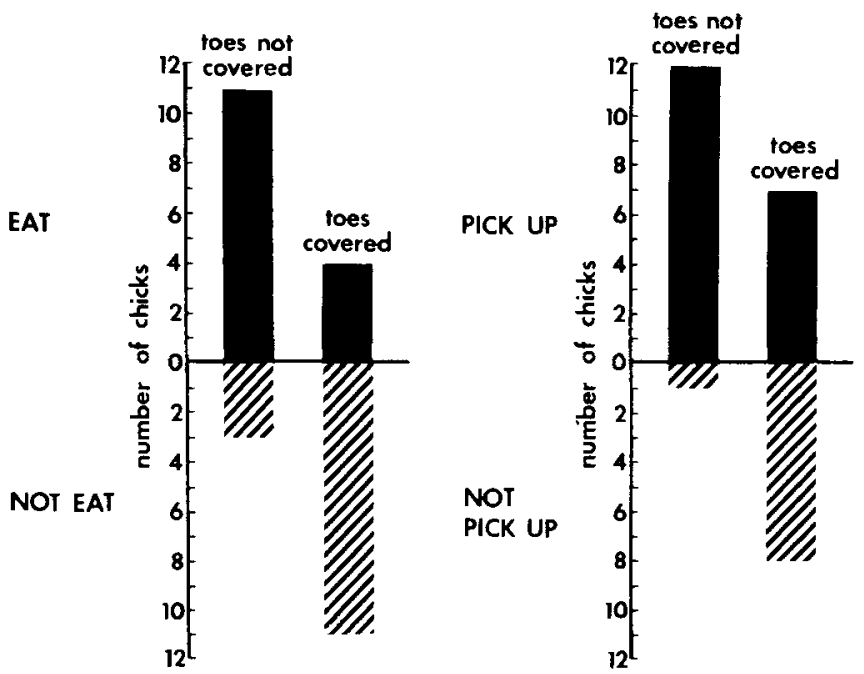

Fig. 2. Frequency of eating and of picking up the mealworm during the 5 -min test in 1 st experiment.

Because chicks raised in isolation are quite variable in the time required to learn to feed, each chick was hand-fed immediately after each test and $6 \mathrm{hr}$ before the next test, with a 3rd daily feeding each morning. Each feeding involved filling the chick's crop with a mixture of chick mash, Gerber's high protein baby food, and water (Kovach, 1969).

Because of the batch-to-batch differences in behavior shown by chicks, the experiment was run 3 times, each time with approximately equal numbers of chicks in the 2 groups.

\section{Results}

On the lst test the probability of the chick eating the mealworm was significantly different between the 2 groups: most of those that saw their toes ate it; most of those with covered toes did not $(p=.007$, Fisher Exact Probability test). This difference disappeared by the second test (covered toes: 8 of 14 ate mealworm; normals: 10 of 14 ate mealworm). (See Fig. 2.)

In addition, the chicks that had not seen their toes were significantly less likely to pick up the mealworms during the test (Fig. 2; $p=.01$, Fisher test) and a smaller proportion of their pecks at the mealworm resulted in them picking it up (median of $38 \%$ vs $83 \%$ for normals; $p<.001$, Mann-Whitney $U$ test). These results may reflect the fact that young chicks give a variety of pecks, ranging from purely exploratory ones that rarely result in picking up the object pecked (the beak probably remaining closed) to ingestive pecks that almost always do. More of the pecks from the foot-covered chicks seemed to be of the exploratory sort. Frequently, the chick would approach the mealworm slowly and peck from such a distance that even with maximum extension of the neck the beak would barely reach the end of the mealworm. 
Another behavior employed in the exploration of novel objects is what Hogan (1965) has called fixating: the chick faces the mealworm, stretches its neck, and turns its head to examine the mealworm with 1 eye at a time. The foot-covered birds fixated the mealworm more than 3 times as long as the normals (foot-covered: median $=6.5 \mathrm{sec}$; normals: median $=1.9 \mathrm{sec} ; p<.05$; Mann-Whitney $U$ test $)$. The latency to fixating the mealworms was shorter in the foot-covered than normal birds (12 $\mathrm{sec}$ vs $70 \mathrm{sec}$ ).

By the 2nd test, the 2 groups did not differ significantly in the behaviors just discussed except that the foot-covered birds more often pecked at the mealworm without picking it up $(p<.05$, Mann-Whitney $U$ test $)$ and their latency to 1 st picking it up was still much longer (median of $200 \mathrm{sec}$ vs $10 \mathrm{sec} ; p<.05$, Mann-Whitney $U$ test). Differences in median time spent fixating (foot-covered: $6 \mathrm{sec} v \mathrm{ss} 1 \mathrm{sec}$ ) and the median latency to eating the mealworm (foot-covered: $234 \mathrm{sec}$ vs $54 \mathrm{sec}$ ) were substantial but not significant.

To confirm the results of this experiment, I performed a 2nd experiment which differed from the one just described only in that the experimental chicks, rather than having their toes covered, had them painted black with model airplane paint (Fig. 1). These chicks could see their toes, but their toes differed from mealworms in color, and in that the segmentation of their toes was less salient than that of normal toes or mealworms. This experiment also served to assuage any doubts that the effect seen in the 1 st experiment might be due to any small impairment in the chick's mobility.

In general, the same types of effects were seen with the black-toed chicks, although the effects were less strong. The median time spent fixating the mealworm was longer in the black-toed chicks than in the normals $(2.7 \mathrm{sec}$ vs $0.6 \mathrm{sec}, p<.01$, Mann-Whitney $U$ ), more pecks were made that did not result in picking up the mealworm $(p<.05$, Mann-Whitney $U$ ), and the proportion of pecks that resulted in picking up the mealworm was lower (median of $73 \%$ vs $94 \%, p<.05$, Mann-Whitney $U$ ). In addition, the latencies to pick up the mealworm (black toes: $49 \mathrm{sec}$ vs normals: $22 \mathrm{sec})$ and to eat it $(73 \mathrm{sec}$ vs $35 \mathrm{sec})$ were longer and the latency to fixate it ( $5 \mathrm{sec}$ vs $25 \mathrm{sec}$ ) was shorter, but these differences are not significant. On the 2nd test differences in the latency to eat the mealworm (black toes: $22 \mathrm{sec}$ vs normals: $12 \mathrm{sec}$, $p<.01$, Mann-Whitney $U)$ and in the amount of fixating $(p<.05$, Mann-Whitney $U)$ were significant.

Unfortunately, perhaps because of seasonal factors, when this experiment was run all the chicks were much more active and much more responsive to the mealworm than in the 1st experiment; this precluded comparing the black-toed chicks to the foot-covered chicks.

\section{Discussion}

In general, both experiments show that if a chick is denied normal visual experience of its toes for 2 days either because they are covered or because they are painted black, the chick is less inclined to pick up or eat a mealworm and more inclined to stare at it (fixating) or give it exploratory pecks. One 5 -min test with a mealworm goes a long way toward eliminating these differences between the groups on 
the next test. These results support the hypothesis that visual experience of its toes perceptually "prepares" a chick for the sight of a mealworm.

Informal observations made in the course of this study suggest that the more impoverished the chick's visual environment, the more difference it makes whether or not it sees its toes. When chicks were raised in a completely white environment with only a small transparent water dish, they showed much more extravagantly ambivalent behavior toward the mealworm: often a chick would stand at the end of the container opposite the mealworm, facing away from it and distress-calling continuously; then suddenly the chick would run up to the mealworm, stretch its neck to its fullest extent, give a quick exploratory peck, and then race back to its previous position facing the wall. These chicks did not pick up the mealworm.

I predict that if these experiments were repeated with the chicks kept in a rich visual environment, no effect would be seen, in that other visual stimuli would provide the same perceptual experiences that the chicks' toes did in this experiment. Unfortunately, the effect described in this paper may not be robust enough to be convenient for an investigation of such interactions of environmental complexity and specific perceptual learning; in pilot experiments, even changing the ambient temperature interfered with the effect.

Although we may be surprised that chicks should be sensitive to the presence or absence of as small a part of their visual world as their feet, we have some reason to regard newly hatched chicks as specialized for visual learning. Hogan (1973a,b) has shown that 3-day-old chicks can rapidly learn to discriminate food from other similar substances. Rogers, Drennen, and Mark (1974) have shown that food grains can be distinguished from very similar-looking gravel in a few minutes. Imprinting, by its nature, involves learning to discriminate the imprinting object from other objects. Several studies have shown that imprinting young chicks to a visual pattern causes a strong and long-lasting improvement in their ability to discriminate that pattern from others, even when the discrimination requires avoidance of the original pattern (Bateson, 1964; Kovach, Fabricius, \& Fält, 1966).

In the present paper, the experience of chicks viewing their feet reduced the novelty of mealworms. This novelty may be of a sort specific to young animals in that the stimuli responsible for the reduction in novelty share with the novel stimuli only perceptual components, not contextual similarity. In contrast, in adults novelty more often resides in the stimulus context.

Other, better documented, examples exist of differences between the perceptual processes of infants and adults. For example, Bateson and Chantrey (1972) and Chantrey (1974) have shown that if before giving young chicks a discrimination test one exposes them repeatedly to both discriminanda within a certain time frame, the discrimination is impaired. They have argued that at that age the chicks are organized to classify 2 closely associated stimuli as being different aspects of one object. If this interpretation proves valid, it might also represent a type of perceptual learning specific to very young animals.

The results presented here are similar to studies with rats in which a learning effect presumably specific to young animals was shown. Rearing rats in the presence of geometric figures enhanced subsequent discrimination of the figures (Bennett, Levitt, \& Anton, 1972; Forgus, 1958a,b; Gibson \& Walk, 1956) and of figures similar to the 
exposed ones (Gibson, Walk, Pick, \& Tighe, 1958). In those experiments, as in these presented in this paper, the animals were raised in visually sparse environments, because exposure to complex environments can produce an even greater enhancement of discrimination than exposure to the forms to be discriminated. (Compare the results of Forgus, 1954, with those of the papers just cited.) Those studies are similar to the present one in that mere exposure to a stimulus affects later familiarity with a novel stimulus that shares certain attributes.

\section{Notes}

This paper is contribution No. 282 from the Institute of Animal Behavior, Rutgers University. The work was supported by an NIMH Center grant to the Institute. I am grateful for the assistance of Ms. Angela Delli Sante and Ms. Evelyn Crish. Carolina.

The work was presented at the 1975 Animal Behavior Society Meeting, Wilmington, North

\section{References}

Bateson, P. P. G. (1964). An effect of imprinting on the perceptual development of domestic chicks. Nature, 202: 421422 .

Bateson, P. P. G., and Chantrey, D. F. (1972). Retardation of discrimination learning in monkeys and chicks previously exposed to both stimuli. Nature, 237: 173-174.

Bennett, T. L., Levitt, L., and Anton, B. S. (1972). Effect of exposure to a single stimulus on transfer of perceptual learning. Percept. Mot. Skills, 34: 559-562.

Chantrey, D. F. (1974). Stimulus preexposure and discrimination learning by domestic chicks: Effect of varying inter-stimulus time. J. Comp. Physiol. Psychol., 87: 517-525.

Chow, K. L., and Stewart, D. L. (1972). Reversal of structural and functional effects of long-term visual deprivation in cats. Exp. Neurol., 34: 409-433.

Forgus, R. H. (1954). The effect of early perceptual learning on the behavioral organization of adult rats. J. Comp. Physiol. Psychol., 47: 331-336.

Forgus, R. H. (1958a). The effect of different kinds of form pre-exposure on form discrimination learning. J. Comp. Physiol. Psychol., 51: 75-78.

Forgus, R. H. (1958b). The interaction between form pre-exposure and test requirements in determining form discrimination. J. Comp. Physiol. Psychol., 51: 588-591.

Gibson, E. J., and Walk, R. D. (1956). The effect of prolonged exposure to visually presented patterns on learning to discriminate them. J. Comp. Physiol. Psychol., 49: 239-242.

Gibson, E. J., Walk, R. D., Pick, H. L., and Tighe, T. J. (1958). The effect of prolonged exposure to visual patterns on learning to discriminate similar and different patterns. J. Comp. Physiol. Psychol, , 51: 584-587.

Hirsch, H. V. B. (1972). Visual perception in cats after environmental surgery. Exp. Brain Res., 15: $405-423$.

Hogan, J. A. (1965). An experimental study of conflict and fear: An analysis of behavior of young chicks towards a mealworm. I. The behavior of chicks which did not eat the mealworm. Behaviour, 25: 45-97.

Hogan, J. A. (1973a). Development of food recognition in young chicks: I. Maturation and nutrition. J. Comp. Physiol. Psychol., 83: 355-366.

Hogan, J. A. (1973b). How young chicks learn to recognize food. In R. A. Hinde \& J. G. Stevenson-Hinde (Eds.), Constraints on Learning: Limitations and Predispositions. London: Academic Press. Pp. 119-139.

Kovach, J. K. (1969). Development of pecking behavior in chicks: recovery after deprivation. $J$. Comp. Physiol. Psychol., 68: 516-523. 
Kovach, J. K., Fabricius, E., and Fält, L. (1966). Relationships between inprinting and perceptual learning. J. Comp. Physiol. Psychol., 61: 449-454.

Muir, D. W., and Mitchell, D. E. (1975). Behavioral deficits in cats following early selected visual exposure to contours of a single orientation. Brain Res., 85:459-477.

Rogers, L. J., Drennen, H. D., and Mark, R. F. (1974). Inhibition of memory formation in the imprinting period: Irreversible action of cycloheximide in young chickens. Brain Res., 79: 213-233.

White, R. E. C. (1971). WRATS: A computer compatible system for automatically recording and transcribing behavioral data. Behaviour, 40: 135-161. 